\title{
Fine tuning of $\pi$-stack separation distances of semiquinone radicals affects their magnetic and electric properties
}

\section{Supporting Information}

\author{
Krešimir Molčanov ${ }^{\mathrm{a}}$, Vladimir Stilinović ${ }^{\mathrm{b}}$, Ana Šantića ${ }^{\mathrm{a}}$, Nadica Maltar-Strmečki ${ }^{\mathrm{a}}$, \\ Damir Pajićc ${ }^{c}$, Biserka Kojić-Prodić ${ }^{a}$ \\ ${ }^{a}$ Rudjer Bošković Institute, Bijenička 54, Zagreb HR-10000, Croatia \\ ${ }^{\mathrm{b}}$ Department of Chemistry, Faculty of Science, University of Zagreb, Horvatovac \\ 102a, Zagreb HR-10000, Zagreb \\ ${ }^{\mathrm{c}}$ Department of Physics, Faculty of Science, University of Zagreb, Bijenička 32, \\ Zagreb HR-10000, Zagreb
}

S1 Molecular structures

S2 IR spectra

S3 Details on crystal packings

S4 Magnetic properties

S5 Electrical conductivity

S6 Experimental details

S7 References 


\section{S1 Molecular structures}

Semiquinone radical anion in triclinic $\mathrm{N}-\mathrm{MePyCl}_{4} \mathrm{Q}(\mathbf{1})$ is located in a general position (symmetry $C_{1}$ ), while in isostructiral orthorhombic 1 and $\mathrm{N}-\mathrm{MePyBr}_{4} \mathrm{Q}(2)$ its crystallographic symmetry is $C i$ (its centroid is located in a crystallographic inversion centre). Molecular structures are shown in Fig. S1; according to bond lengths (Table S1), they are approximately half-way between quinoid and aromatic. There is no significant geometrical discrepancy compared to the semiquinones in previously published alkali salts ${ }^{1-3}$ (i.e. differences are within experimental error). According to Cremer-Pople puckering parameter $\tau^{4}$ (Table S1), the rings can be regarded as essentially planar, which was also the case for the alkali salts ${ }^{1-3}$. However, a side-view (Fig. S3) of the rings reveals that in triclinic 1 the ring is slighty bent, while in orthorombic $\mathbf{1}$ and $\mathbf{2}$ it resembles a very shallow chair. The bending is probably a result of close interaction with spin coupling in a pair of radicals; it was also observed in diamagnetic alkali salts with closely interacting dimers, $\mathrm{KCl}_{4} \mathrm{Q} \cdot \mathrm{Me}_{2} \mathrm{CO}$ and $\mathrm{RbCl}_{4} \mathrm{Q} \cdot \mathrm{Me}_{2} \mathrm{CO}{ }^{1}$. In antiferromagnetic salts, where no pairing occurs, but stacks of equidistant radicals are formed, such as high-temperature form of $\mathrm{KCl}_{4} \mathrm{Q} \cdot \mathrm{Me}_{2} \mathrm{CO}$ and $\mathrm{NH}_{4} \mathrm{Cl}_{4} \mathrm{Q} \cdot \mathrm{MeCN}^{2}$, rings are not bent and $\tau$ is usually less than $1^{\circ}$. 


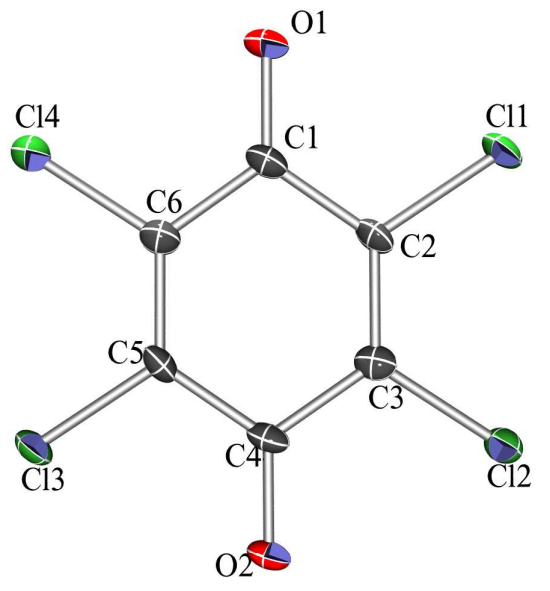

a)

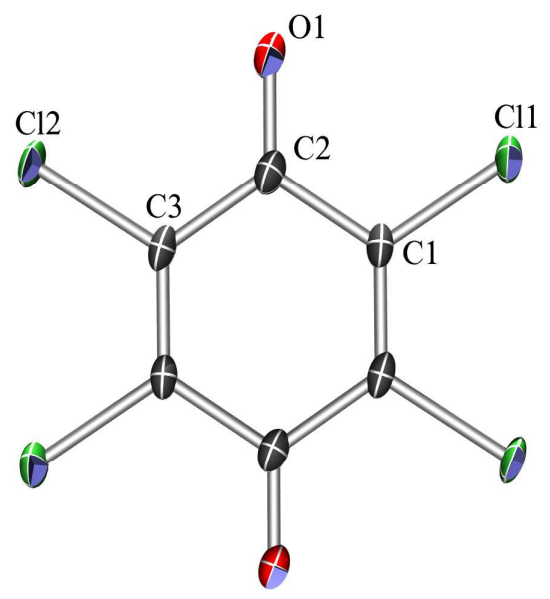

c)

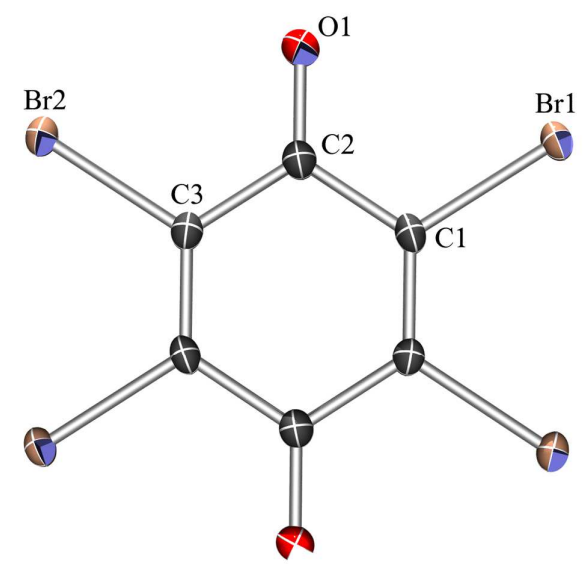

e)

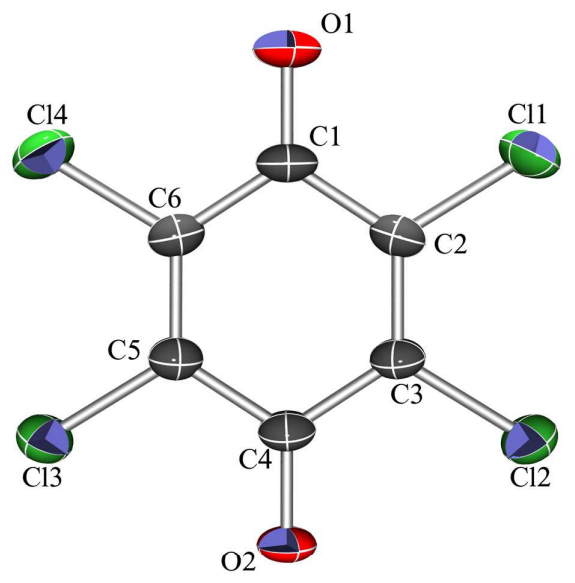

b)

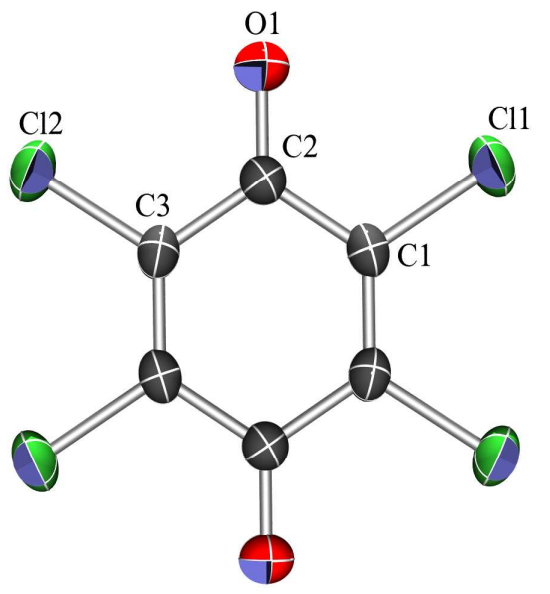

d)

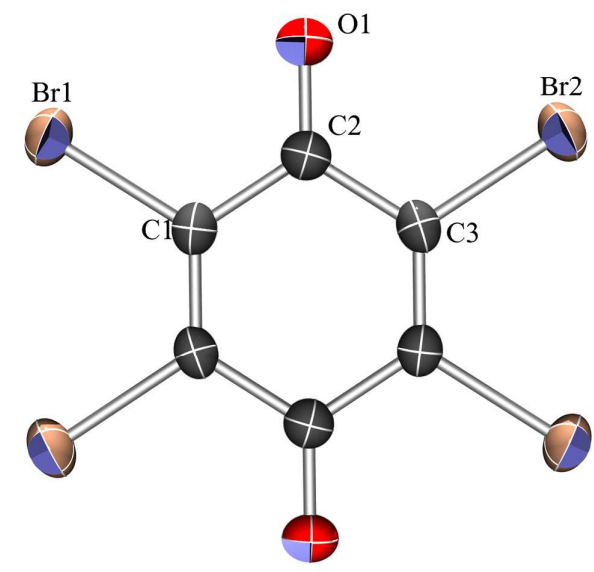

f)

Figure S1 ORTEP-3 ${ }^{5}$ drawings of semiquinone radical anion in a) triclinic 1, $100 \mathrm{~K}$; b) triclinic 1, RT; c) orthorhombic 1, $100 \mathrm{~K}$; d) orthorhombic 1, RT; e) orthorhombic 2, $100 \mathrm{~K}$; f) orthorhombic 2, RT. Displacement ellipsoids are drawn for the probability of $50 \%$. 


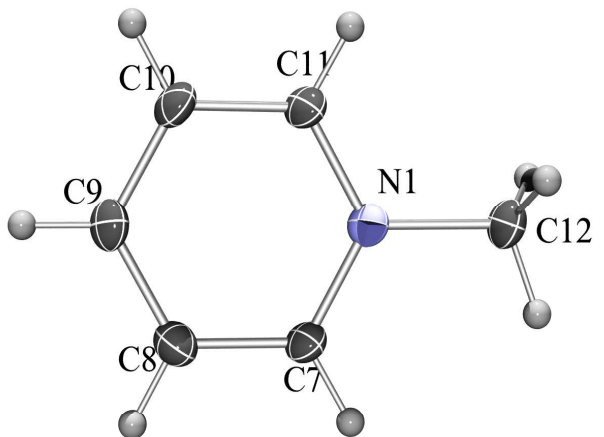

a)

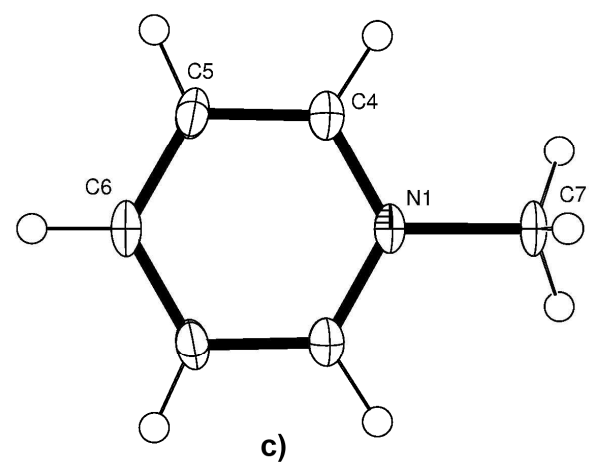

c)

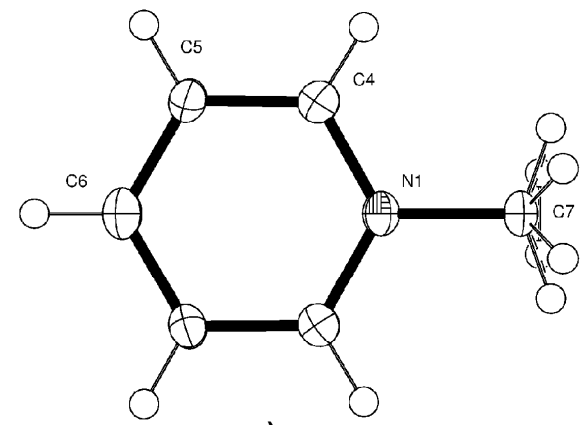

e)

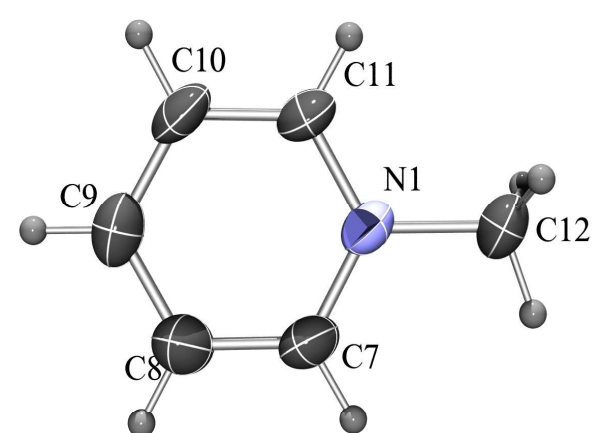

b)

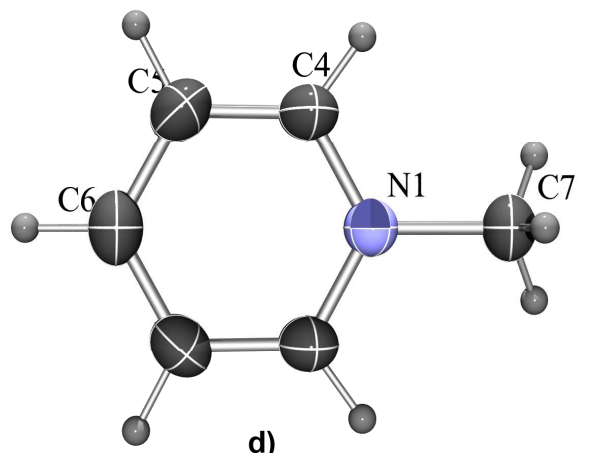

d)

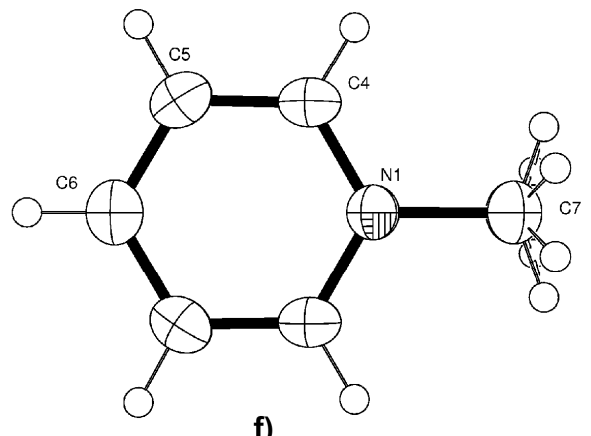

f)

Figure S2 ORTEP- $3{ }^{5}$ drawings of N-methylpyridinium cation in a) triclinic 1, $100 \mathrm{~K}$;

b) triclinic 1, RT; c) orthorhombic 1, $100 \mathrm{~K}$; d) orthorhombic 1, RT; e) orthorhombic 2, $100 \mathrm{~K}$; f) orthorhombic 2, RT. Displacement ellipsoids are drawn for the probability of $50 \%$. 


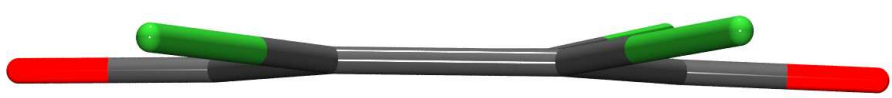

a)

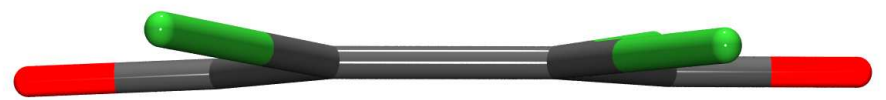

b)

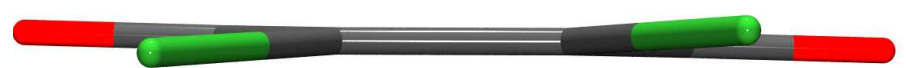

c)

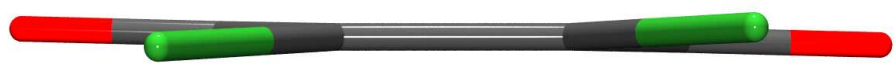

d)

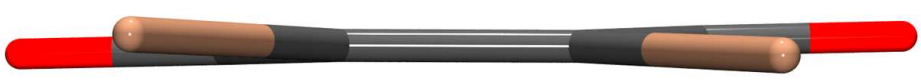

e)

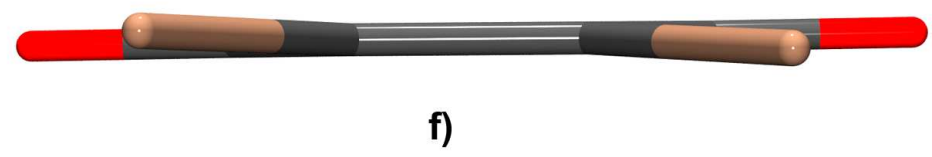

Figure S3 Side-view of semiquinone radical a) triclinic 1, $100 \mathrm{~K}$; b) triclinic 1, RT; c) orthorhombic 1, $100 \mathrm{~K}$; d) orthorhombic 1, RT; e) orthorhombic 2, $100 \mathrm{~K}$; f) orthorhombic 2, RT showing different conformation of $\mathrm{Cl}_{4} \mathrm{Q}^{*-}$ due to spin pairing. 
Table S1 Geometric parameters $\left(\AA,^{\circ}\right)$ of semiquinone radical anions. Atom numbering for orthorhombic structures (anion symmetry $\mathrm{C} i$ ) has been altered to correspond to the triclinic one (anion symmetry $C_{1}$ ).

\begin{tabular}{lllll}
\hline & $\mathbf{1}$, triclinic, & $\mathbf{1}$, triclinic, & $\mathbf{1}$, orthorhombic, & $\mathbf{1}$, orthorhombic, \\
& $100 \mathrm{~K}$ & $\mathrm{RT}$ & $100 \mathrm{~K}$ & $\mathrm{RT}$ \\
\hline C1 - C2 & $1.459(5)$ & $1.456(4)$ & $1.462(4)$ & $1.449(2)$ \\
C2 - C3 & $1.360(4)$ & $1.362(3)$ & $1.361(4)$ & $1.360(2)$ \\
C3 - C4 & $1.458(4)$ & $1.454(3)$ & $1.452(4)$ & $1.454(2)$ \\
C4 - C5 & $1.458(5)$ & $1.460(3)$ & $1.462(4)^{*}$ & $1.449(2)^{*}$ \\
C5 - C6 & $1.359(4)$ & $1.368(3)$ & $1.361(4)^{*}$ & $1.360(2)^{*}$ \\
C6 - C1 & $1.455(4)$ & $1.454(3)$ & $1.452(4)^{*}$ & $1.454(2)^{*}$ \\
C1 - O1 & $1.246(4)$ & $1.244(3)$ & $1.239(4)$ & $1.245(2)$ \\
C4 - O2 & $1.251(4)$ & $1.246(3)$ & $1.239(4) *$ & $1.245(2)^{*}$ \\
Puckering & 4.0 & 4.2 & 1.5 & 1.6 \\
parameter $\tau$ & & & & \\
\hline
\end{tabular}

* Symmetry equivalent

Table S1 Cont'd.

\begin{tabular}{lll}
\hline & 2, orthorhombic, 100 K & 2, orthorhombic, RT \\
\hline C1 - C2 & $1.456(5)$ & $1.453(5)$ \\
C2 - C3 & $1.359(5)$ & $1.359(5)$ \\
C3 - C4 & $1.458(5)$ & $1.455(5)$ \\
C4 - C5 & $1.456(5)^{*}$ & $1.453(5)^{*}$ \\
C5 - C6 & $1.359(5)^{*}$ & $1.359(5)^{*}$ \\
C6 - C1 & $1.458(5)^{*}$ & $1.455(5)^{*}$ \\
C1 - O1 & $1.244(5)$ & $1.245(5)$ \\
C4 - O2 & $1.244(5)^{*}$ & $1.245(5)^{*}$ \\
Puckering & 3.0 & 0.7 \\
parameter $\tau$ & & \\
\hline
\end{tabular}

* Symmetry equivalent 


\section{S2 IR spectra}

Table S2 Assignment of the major absorption bands in the IR-spectra of $\mathbf{1}$ and $\mathbf{2}$. Absorption bands of neutral $\mathbf{B r}_{4} \mathbf{Q}^{6}$ have been given for comparison.

\begin{tabular}{|c|c|c|c|}
\hline & 1 & 2 & $\mathbf{B r}_{4} \mathbf{Q}^{6}$ \\
\hline$v(\mathrm{C}-\mathrm{H})^{\mathrm{f}}$ & $3425 \mathrm{~s}$ & $3424 \mathrm{~s}$ & \\
\hline$v(\mathrm{C}-\mathrm{H})^{\mathrm{f}}$ & $3137 \mathrm{~m}$ & $3131 \mathrm{w}$ & \\
\hline$v(\mathrm{C}-\mathrm{H})^{\mathrm{f}}$ & $3058 \mathrm{~s}$ & $3041 \mathrm{~s}$ & \\
\hline$v(\mathrm{C}=\mathrm{O})^{\mathrm{b}}$ or $v(\mathrm{C}=\mathrm{C})^{\mathrm{a}}$ & $1680 \mathrm{w}$ & $1667 \mathrm{vs}$ & 1687 \\
\hline$v(\mathrm{C}=\mathrm{O})^{\mathrm{b}}$ & $1634 \mathrm{~m}$ & $1634 \mathrm{~s}$ & \\
\hline$v(\mathrm{C}=\mathrm{C})^{\mathrm{b}, \mathrm{e}}$ & 1537 vs & $1543 \mathrm{~s}$ & 1577 \\
\hline$v(\mathrm{C}=\mathrm{O})+v(\mathrm{C}=\mathrm{C})^{\mathrm{g}}$ & & $1529 \mathrm{~s}$ & \\
\hline$v(\mathrm{C}=\mathrm{C})^{\mathrm{b}, \mathrm{e}, \mathrm{g}}$ & $1502 \mathrm{~m}$ & $1490 \mathrm{~s}$ & 1539 \\
\hline$v_{\mathrm{as}}(\mathrm{C}=\mathrm{C})^{\mathrm{e}}$ & $1475 \mathrm{~s}$ & $1481 \mathrm{~s}$ & \\
\hline$v_{\text {as }}(\mathrm{C}=\mathrm{C}, \text { aromatic })^{\mathrm{f}}$ & $1428 \mathrm{sh}$ & $1428 \mathrm{~m}$ & \\
\hline$v(\mathrm{C}-\mathrm{C})^{\mathrm{b}, \mathrm{e}}$ & $1365 \mathrm{w}$ & $1383 \mathrm{w}$ & \\
\hline$v(\mathrm{C}-\mathrm{C})^{\mathrm{b}}$ & $1280 \mathrm{w}$ & $1285 \mathrm{~m}$ & \\
\hline$v(\mathrm{C}-\mathrm{C})+\delta(\mathrm{OCC})^{\mathrm{d}}$ & & $1208 \mathrm{~s}$ & 1176,1169 \\
\hline$\delta(\mathrm{C}-\mathrm{H})^{\mathrm{f}}$ & $1181 \mathrm{w}$ & $1191 \mathrm{~s}$ & \\
\hline$\delta(\mathrm{C}-\mathrm{H})^{\mathrm{f}}$ & $1165 \mathrm{w}$ & & \\
\hline$v(\mathrm{C}-\mathrm{N}) \mathrm{f}+v(\mathrm{C}-\mathrm{C})^{\mathrm{d}}$ & $1139 \mathrm{~s}$ & & \\
\hline$v(\mathrm{C}=\mathrm{C})+v(\mathrm{C}-\mathrm{Br})^{\mathrm{g}}$ & & $1097 \mathrm{~m}$ & \\
\hline$\delta(\mathrm{C}-\mathrm{H}), \delta(\mathrm{C}-\mathrm{C})^{\mathrm{f}}$ & $1029 \mathrm{w}$ & $1048 \mathrm{~s}$ & 1040 \\
\hline $\mathrm{r}\left(\mathrm{CH}_{3}\right)^{\mathrm{g}}$ & $989 \mathrm{~s}$ & & \\
\hline$\delta(\mathrm{C}-\mathrm{C}), v(\mathrm{C}-\mathrm{Cl})^{\mathrm{g}}$ & $940 \mathrm{w}$ & & \\
\hline$\delta(\mathrm{C}-\mathrm{C}), v(\mathrm{C}-\mathrm{Br})^{\mathrm{g}}$ & & $926 \mathrm{w}$ & \\
\hline$v(\mathrm{C}-\mathrm{H})^{\mathrm{f}}+v(\mathrm{C}-\mathrm{C})^{\mathrm{d}}$ & $909 \mathrm{~s}$ & & \\
\hline$v(\mathrm{C}-\mathrm{Cl})+\delta(\mathrm{OCC})^{\mathrm{d}}$ & $858 \mathrm{w}$ & & \\
\hline$\delta(\mathrm{CCC})+v(\mathrm{C}-\mathrm{Br})^{\mathrm{g}}$ & & $872 \mathrm{~m}$ & 906 \\
\hline$\delta(\mathrm{OCC})^{\mathrm{b}}$, ring chair & $766 \mathrm{~m}$ & $765 \mathrm{~s}$ & \\
\hline bend & & & \\
\hline$v(\mathrm{C}-\mathrm{Br}), \delta(\mathrm{CCC})^{\mathrm{g}}$ & & & 750 \\
\hline$\delta(\mathrm{OCC})^{\mathrm{b}}$ & $720 \mathrm{~m}$ & & \\
\hline
\end{tabular}




\begin{tabular}{|c|c|c|c|}
\hline$\delta(\mathrm{OCC})^{b}$ & $689 \mathrm{w}$ & & \\
\hline$\delta(\mathrm{OCC})^{\mathrm{b}}, \delta(\mathrm{CCBr})^{\mathrm{g}}$ & & $689 \mathrm{w}$ & 694 \\
\hline$\tau(\mathrm{OCCBr})^{\mathrm{g}}$ & & $674 \mathrm{~s}$ & \\
\hline$v(\mathrm{C}-\mathrm{Cl})^{\mathrm{e}}$ & $669 \mathrm{w}$ & & \\
\hline$v(\mathrm{C}-\mathrm{Cl})^{\mathrm{e}}$ & $649 \mathrm{w}$ & & \\
\hline$v(\mathrm{C}-\mathrm{Br})^{\mathrm{g}}$ & & $623 \mathrm{~m}$ & 617 \\
\hline$\delta(\mathrm{OCC}), v(\mathrm{C}-\mathrm{Br})^{\mathrm{g}}$ & $487 \mathrm{~m}$ & $470 \mathrm{w}$ & \\
\hline$\delta(\mathrm{C}-\mathrm{C}-\mathrm{C})^{\mathrm{b}}, \delta(\mathrm{OCC})^{\mathrm{c}}$ & $461 \mathrm{w}$ & $461 \mathrm{w}$ & 474 \\
\hline$v(\mathrm{C}-\mathrm{Cl})^{\mathrm{b}}, \delta(\mathrm{OCC})^{\mathrm{c}}$ & $444 \mathrm{w}$ & & \\
\hline$v(\mathrm{C}-\mathrm{Br})^{\mathrm{g}}, \delta(\mathrm{OCC})^{\mathrm{c}}$ & & $444 \mathrm{~m}$ & \\
\hline
\end{tabular}

a Assignation according to Miller \& Dixon, $1987^{7}$.

b Assignation according to Boesch \& Wheeler, $1997^{8}$.

c Assignation according to Boesch \& Wheeler, $1995^{9}$.

$\mathrm{d}$ Assignation according to Zhang et al., $2013^{10}$.

e Our assignation according to our B3LYP calculations ${ }^{3}$.

f $N$-MePy band, assignation according to Arenas et al., $1996^{11}$.

$\mathrm{g} \mathrm{Br}_{4} \mathrm{Q}^{-}$assignation, according to ${ }^{6}$. 


\section{S3 Additional details on crystal packing and stacking of semiquinone radicals}

In triclinic polymorph of $\mathbf{1}$ (Fig. S4a) stacks of radical anions parallel to [100] are separated by $N$-MePy cations arranged into $\pi$-stacked pairs. Side-view of a radical stack reveals alternating longer and shorter inter-ring distances (Fig. S5a, Table S3). This can be interpreted as stacking of strongly-bound radical dimers with paired spins, and is consistent with diamagnetic properties. Similar stacks of dimers were already observed in similar diamagnetic salts of semiquinone radicals ${ }^{1-3}$.

In isostructural orthorhombic packings of 1 and 2 (Fig S4b, S5b) there are infinite stacks of radicals separated by infinite stacks of $N$-MePy cations, both extending in the direction [001]. The stacked radicals are equidistant, with interplanar separation shorter than $3.30 \AA$ (Table S3), which is considered to be critical distance for spin coupling. Such a structure is consistent with antiferromagnetic properties of the crystals. However, due to the presence of stacks of sterically bulky $N$-MePy cations, there are no magnetic interactions between the radical stacks. Therefore, the crystals are 1D antiferromagnetic, and a small magnetic susceptibility is a result of a single unpaired spin per stack (since some stacks may have an odd number of radicals). 


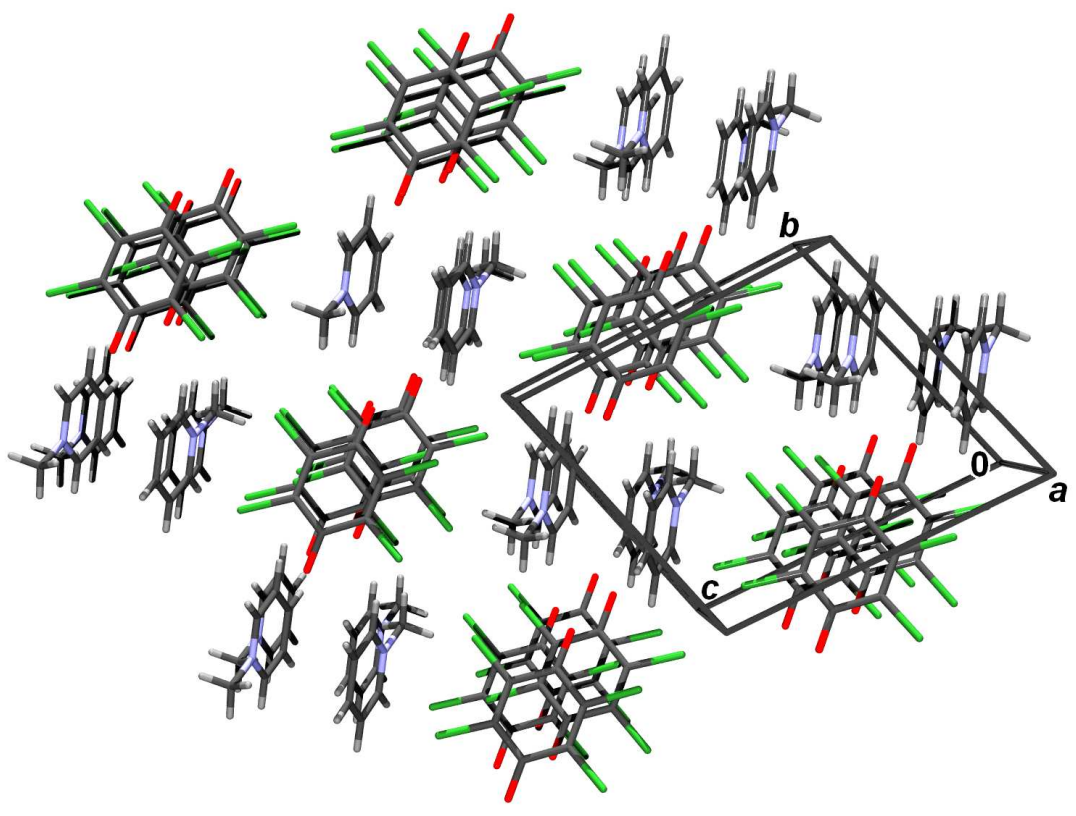

a)

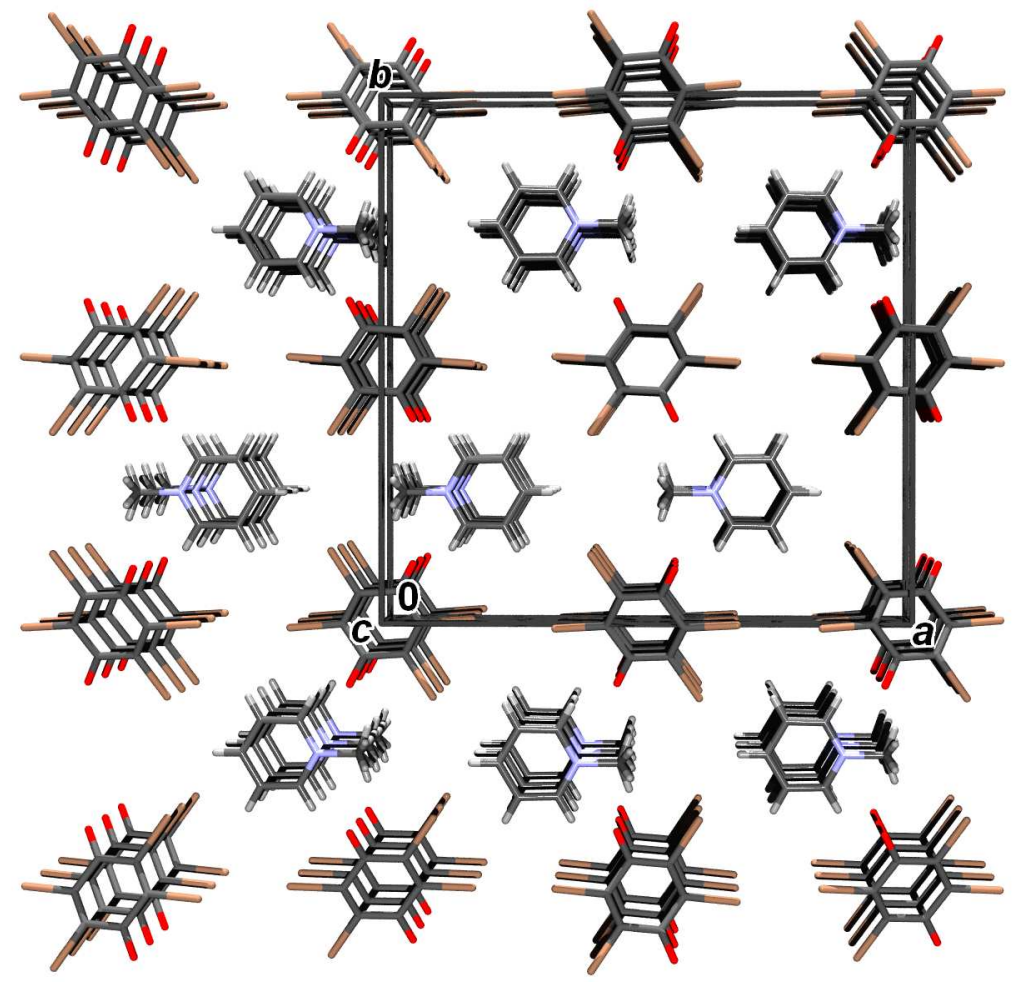

b)

Figure S4 Crystal packing of a) triclinic 1 and b) orthorhombic 2 showing separated stacks of radical anions and $N$-MePy cations. Packing of orthorhombic $\mathbf{1}$ is isostructural to 2 . 


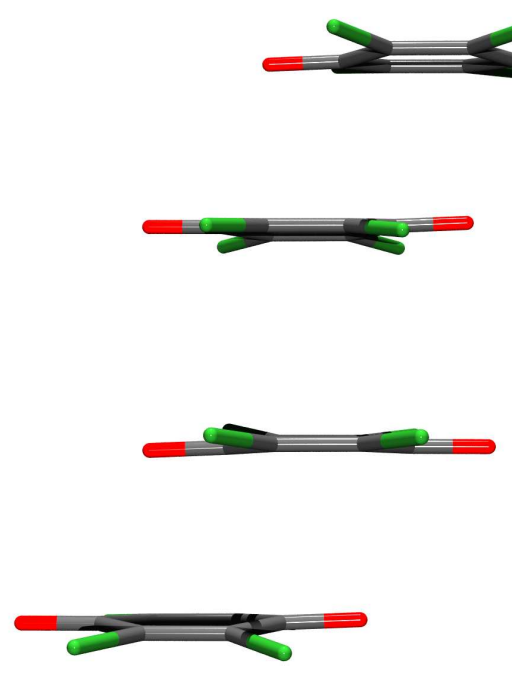

a)

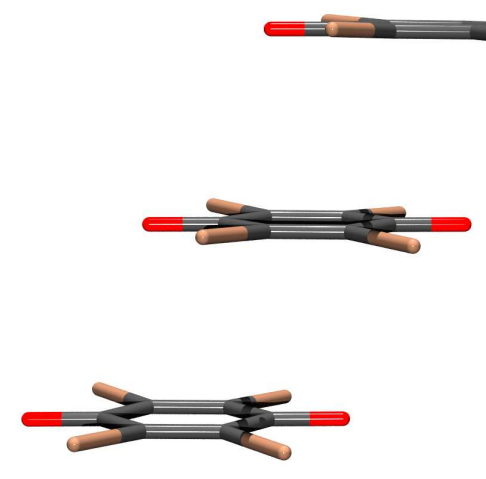

b)

Figure S5 Stacks of anion radicals a) dimers with diamagnetical spin coupling in triclinic $\mathbf{1}$ and b) equidistant radicals with antiferromagnetic coupling in orthorhombic 2. 
Table S3 Geometric parameters of the $\pi \cdots \pi$ interactions. Symmetry operators: $i$ ) $-x$, $1-y,-z:$ ii) $x, 3 / 2-y, z$.

\begin{tabular}{|c|c|c|c|c|c|c|}
\hline$\pi \cdots \pi$ & $\mathrm{Cg}^{\mathrm{a}} \cdots \mathrm{Cg} / \AA$ & $\alpha^{b}$ & $\beta^{\mathrm{c}}$ & Cg*plane $(\mathrm{Cg} 2) / \AA$ & Offset/ $\AA$ & Symm. op. on Cg2 \\
\hline \multicolumn{7}{|l|}{ 1, triclinic, $100 \mathrm{~K}$} \\
\hline $\mathrm{C} 1 \rightarrow \mathrm{C} 6 \cdots \mathrm{C} 1 \rightarrow \mathrm{C} 6$ short & $3.535(2)$ & 0 & 35.90 & $2.8634(16)$ & 2.074 & $1-x, 2-y, 1-z$ \\
\hline $\mathrm{C} 1 \rightarrow \mathrm{C} 6 \cdots \mathrm{C} 1 \rightarrow \mathrm{C} 6$ long & $4.583(2)$ & 0 & 38.20 & $3.6008(16)$ & 2.834 & $-x, 2-y, 1-z$ \\
\hline $\mathrm{N} 1 \rightarrow \mathrm{C} 11 \cdots \mathrm{N} 1 \rightarrow \mathrm{C} 11$ & $3.555(2)$ & 0 & 14.70 & $3.4391(15)$ & 0.902 & $-1-x, 1-y, 2-z$ \\
\hline \multicolumn{7}{|l|}{ 1, triclinic, RT } \\
\hline $\mathrm{C} 1 \rightarrow \mathrm{C} 6 \cdots \mathrm{C} 1 \rightarrow \mathrm{C} 6$ short & $3.5670(13)$ & 0 & 35.51 & $2.9036(10)$ & 2.072 & $1-x, 2-y, 1-z$ \\
\hline $\mathrm{C} 1 \rightarrow \mathrm{C} 6 \cdots \mathrm{C} 1 \rightarrow \mathrm{C} 6$ long & $4.5896(14)$ & 0 & 37.06 & $3.6626(10)$ & 2.766 & $-x, 2-y, 1-z$ \\
\hline $\mathrm{N} 1 \rightarrow \mathrm{C} 11 \cdots \mathrm{N} 1 \rightarrow \mathrm{C} 11$ & $3.6094(18)$ & 0 & 12.13 & $3.5288(12)$ & 0.759 & $-1-x, 1-y, 2-z$ \\
\hline \multicolumn{7}{|l|}{ 1, orthorhombic, $100 \mathrm{~K}$} \\
\hline $\mathrm{C} 1 \rightarrow \mathrm{C} 3^{i} \cdots \mathrm{C} 1 \rightarrow \mathrm{C} 3^{i}$ & $3.776(2)$ & 0 & 33.20 & $3.1587(13)$ & 2.069 & $\mathrm{x}, y,-1+z$ \\
\hline $\mathrm{N} 1 \rightarrow \mathrm{C} 4^{i i} \cdots \mathrm{N} 1 \rightarrow \mathrm{C} 4^{i i}$ & $3.776(2)$ & 0 & 4.2 & $3.7655(14)$ & 0.279 & $\mathrm{x}, y,-1+z$ \\
\hline \multicolumn{7}{|l|}{ 1, orthorhombic, RT } \\
\hline $\mathrm{C} 1 \rightarrow \mathrm{C} 3^{i} \cdots \mathrm{C} 1 \rightarrow \mathrm{C} 3^{i}$ & $3.8411(10)$ & 0 & 32.40 & $3.2430(7)$ & 2.058 & $\mathrm{x}, y,-1+z$ \\
\hline $\mathrm{N} 1 \rightarrow \mathrm{C} 4^{i i} \cdots \mathrm{N} 1 \rightarrow \mathrm{C} 4^{i i}$ & $3.8411(10)$ & 0 & 3.0 & $3.8359(9)$ & 0.200 & $\mathrm{x}, y,-1+z$ \\
\hline \multicolumn{7}{|l|}{ 2, orthorhombic, $100 \mathrm{~K}$} \\
\hline $\mathrm{C} 1 \rightarrow \mathrm{C} 3^{i} \cdots \mathrm{C} 1 \rightarrow \mathrm{C} 3^{i}$ & $3.895(6)$ & 0 & 32.49 & $3.2855(16)$ & 2.092 & $-\mathrm{x}, 1-y, 1-z$ \\
\hline $\mathrm{N} 1 \rightarrow \mathrm{C} 4^{i i} \cdots \mathrm{N} 1 \rightarrow \mathrm{C} 4^{i i}$ & $3.895(6)$ & 0 & 2.29 & $3.8919(17)$ & 0.156 & $x, 3 / 2-y,-1+z$ \\
\hline \multicolumn{7}{|l|}{ 2, orthorhombic, RT } \\
\hline $\mathrm{C} 1 \rightarrow \mathrm{C}^{i} \cdots \mathrm{C} 1 \rightarrow \mathrm{C}^{i}$ & $3.959(2)$ & 0 & 31.60 & $3.3720(15)$ & 2.075 & $-\mathrm{x}, 1-y, 1-z$ \\
\hline $\mathrm{N} 1 \rightarrow \mathrm{C} 4^{i i} \cdots \mathrm{N} 1 \rightarrow \mathrm{C} 4^{i i}$ & $3.959(3)$ & 0 & 1.52 & $3.9577(19)$ & 0.105 & $x, 3 / 2-y,-1+z$ \\
\hline
\end{tabular}

${ }^{\mathrm{a}} \mathrm{Cg}=$ centre of gravity of the aromatic ring.

${ }^{\mathrm{b}} \alpha=$ angle between planes of two aromatic rings.

${ }^{\mathrm{c}} \beta=$ angle between $\mathrm{Cg} \cdots \mathrm{Cg}$ line and normal to the plane of the first aromatic ring. 
S4 Magnetic properties
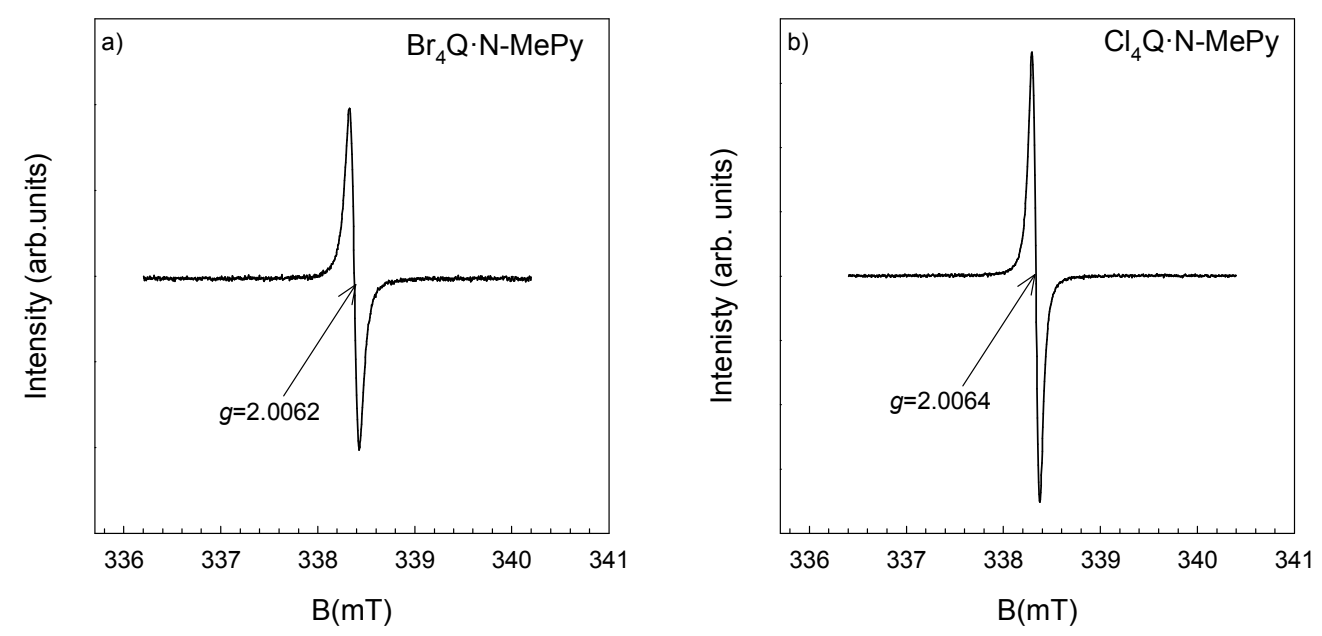

Figure S6 EPR spectra of single crystal a) 2 and b) orthorhombic 1 recorded in the plane at room temperature.

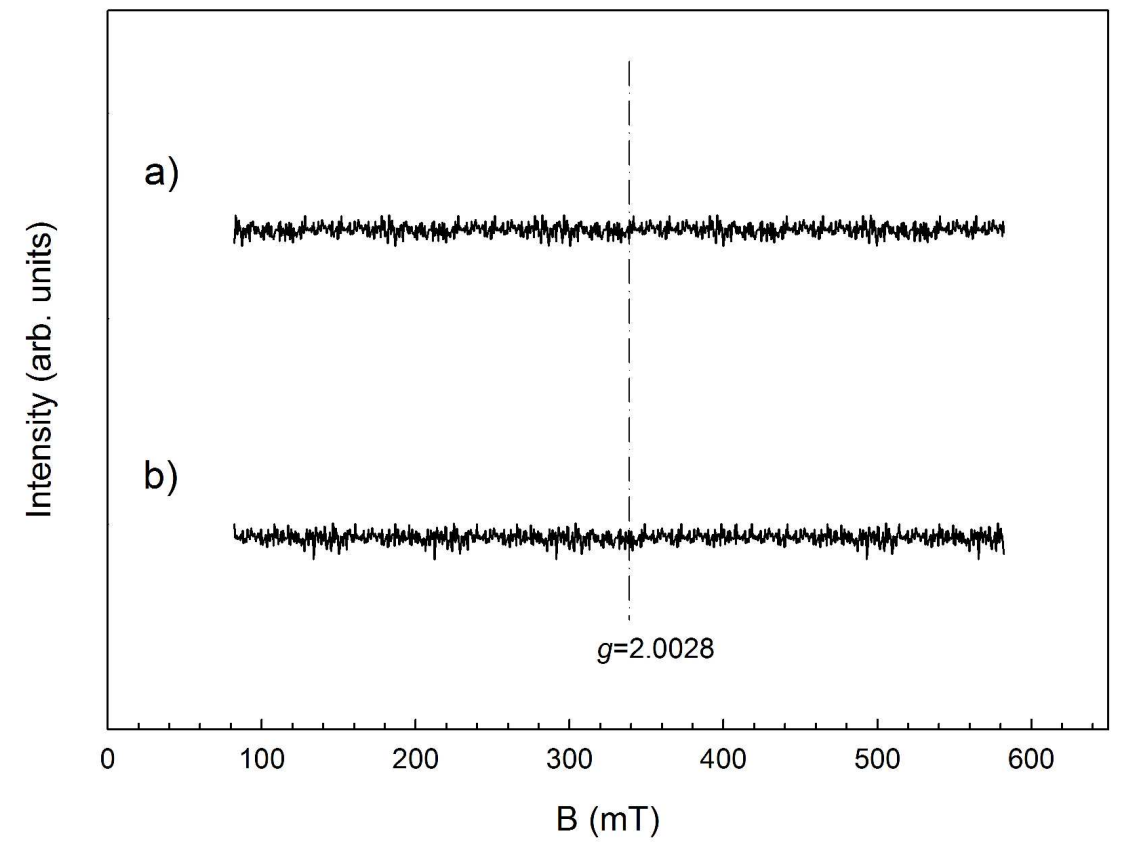

Figure S7 EPR spectra of a) an empty EPR tube and b) crystal of triclinic polymorph of 1 recorded at room temperature. 


\section{S5 Electrical conductivity}
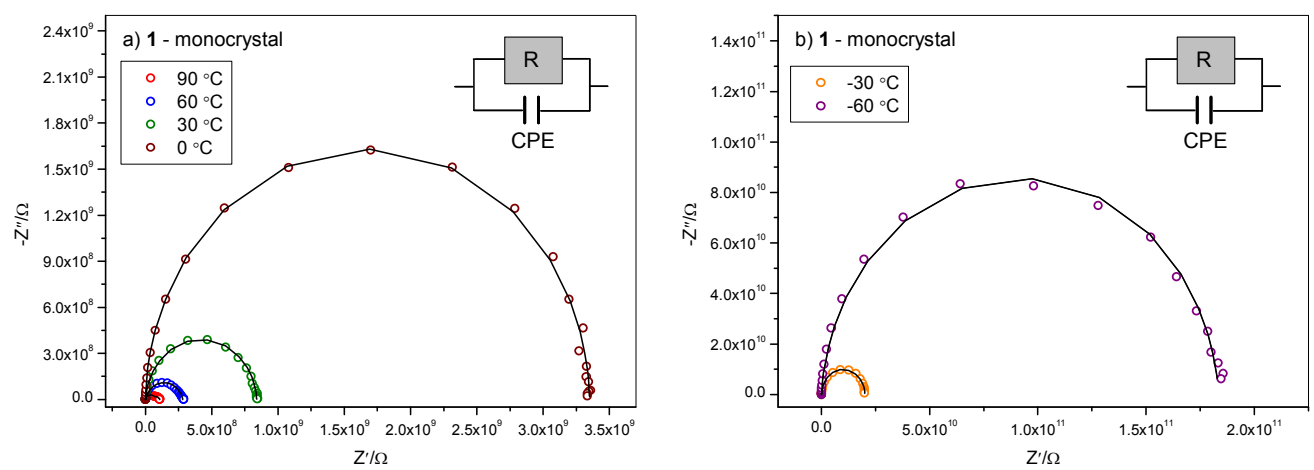

Figure S8 Impedance spectra at different temperatures and corresponding equivalent circuits for single crystal of orthorhombic 1. Single impedance semicircle observed at all temperatures can be approximated by an equivalent circuit that consists of a resistor (R) and a constant phase element (CPE) in parallel. Circles denote experimental values; solid lines correspond to the best fit. The fitting parameters are given in Table S4 of the Supporting Information.
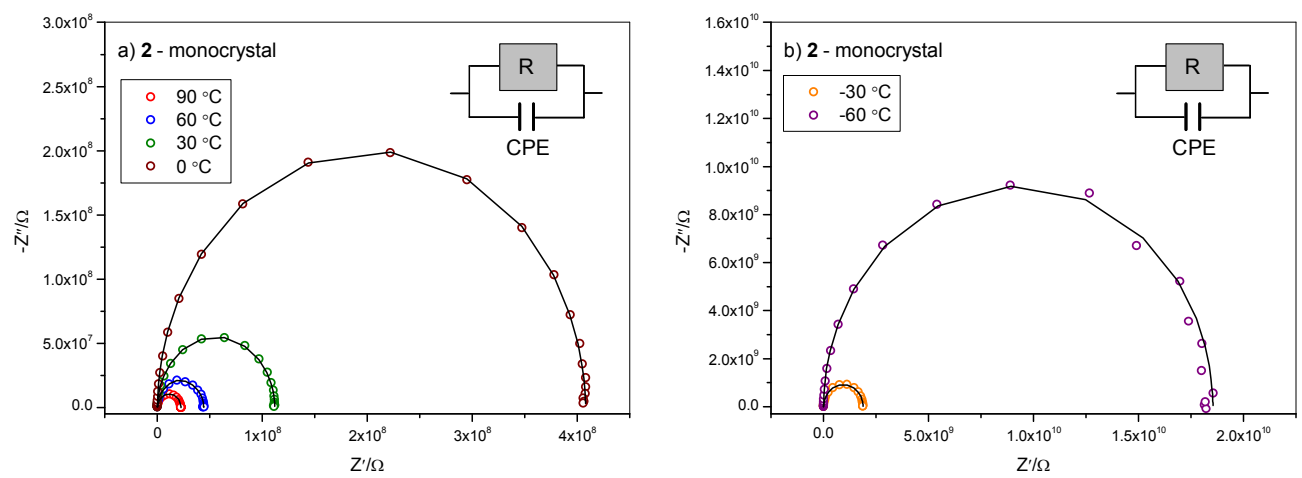

Figure S9 Impedance spectra at different temperatures and corresponding equivalent circuits for single crystal of compound 2 . Single impedance semicircle observed at all temperatures can be approximated by an equivalent circuit that consists of a resistor (R) and a constant phase element (CPE) in parallel. Circles denote experimental values; solid lines correspond to the best fit. The fitting parameters are given in Table S4 of the Supporting Information. 
Table S4 The fitting parameters of impedance spectra at different temperatures and calculated electrical conductivities for the single crystals of orthorhombic $\mathbf{1}$ and $\mathbf{2}$.

\begin{tabular}{|c|c|c|c|c|c|}
\hline \multirow[t]{2}{*}{ Sample } & \multirow[t]{2}{*}{$\mathrm{T}^{\circ}(\mathrm{C})$} & \multirow[t]{2}{*}{$R / \Omega$} & \multicolumn{2}{|c|}{$C P E$} & \multirow[t]{2}{*}{$\sigma_{\mathrm{DC}} /(\Omega \mathrm{cm})-1$} \\
\hline & & & $A / \mathrm{s}^{\alpha} \Omega^{-1}$ & $\alpha$ & \\
\hline \multirow{7}{*}{$\begin{array}{c}\text { orthorhombic } 1 \\
\text { single crystal }\end{array}$} & 90 & $1.07 \times 10^{8}$ & $3.96 \times 10^{-12}$ & 0.97 & $5.05 \times 10^{-6}$ \\
\hline & 60 & $2.89 \times 10^{8}$ & $3,07 \times 10^{-12}$ & 0.98 & $1.87 \times 10^{-6}$ \\
\hline & 30 & $8.21 \times 10^{8}$ & $3.71 \times 10^{-12}$ & 0.95 & $6.59 \times 10^{-7}$ \\
\hline & 0 & $3.35 \times 10^{9}$ & $2.90 \times 10^{-12}$ & 0.98 & $1.62 \times 10^{-7}$ \\
\hline & -30 & $2.00 \times 10^{10}$ & $2.68 \times 10^{-12}$ & 0.99 & $2.70 \times 10^{-8}$ \\
\hline & -60 & $1.84 \times 10^{11}$ & $2.74 \times 10^{-12}$ & 0,96 & $2.94 \times 10^{-9}$ \\
\hline & -90 & $4.19 \times 10^{12}$ & $2.44 \times 10^{-12}$ & 0.96 & $1.92 \times 10^{-10}$ \\
\hline \multirow{7}{*}{$\begin{array}{c}\mathbf{2} \\
\text { single crystal }\end{array}$} & 90 & $2.26 \times 10^{7}$ & $4.81 \times 10^{-12}$ & 0.95 & $4.74 \times 10^{-5}$ \\
\hline & 60 & $4.34 \times 10^{7}$ & $3.69 \times 10^{-12}$ & 0.97 & $2.47 \times 10^{-5}$ \\
\hline & 30 & $1.14 \times 10^{8}$ & $3.00 \times 10^{-12}$ & 0.99 & $9.39 \times 10^{-6}$ \\
\hline & 0 & $4.05 \times 10^{8}$ & $2.92 \times 10^{-12}$ & 0.99 & $2.65 \times 10^{-6}$ \\
\hline & -30 & $1.88 \times 10^{9}$ & $2.72 \times 10^{-12}$ & 0.99 & $5.70 \times 10^{-7}$ \\
\hline & -60 & $1.86 \times 10^{10}$ & $2.61 \times 10^{-12}$ & 0.99 & $5.77 \times 10^{-8}$ \\
\hline & -90 & $2.74 \times 10^{11}$ & $2.65 \times 10^{-12}$ & 0.95 & $3.91 \times 10^{-9}$ \\
\hline
\end{tabular}



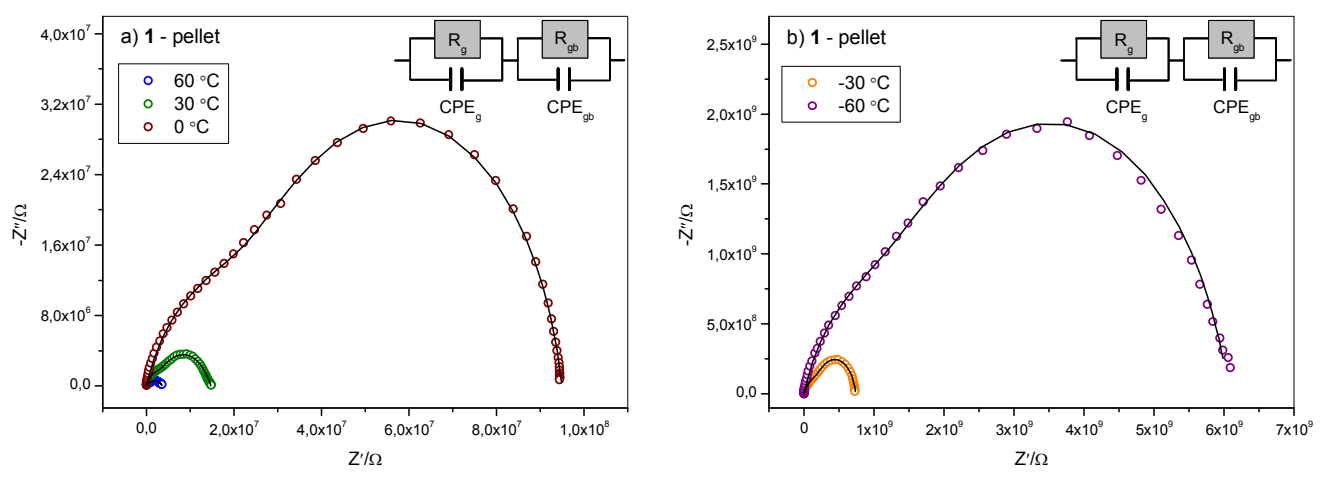

Figure S10 Impedance spectra at different temperatures and corresponding equivalent circuits for the pellet of compound $\mathbf{1}$. The two impedance semicircles observed at all temperatures can be approximated by a series of two parallel R-CPE elements. The high frequency semicircle corresponds to the crystalline grains, while, low frequency one corresponds to the grain boundary. Circles denote experimental values; solid lines correspond to the best fit. The fitting parameters are given in Table S5 of the Supporting Information.
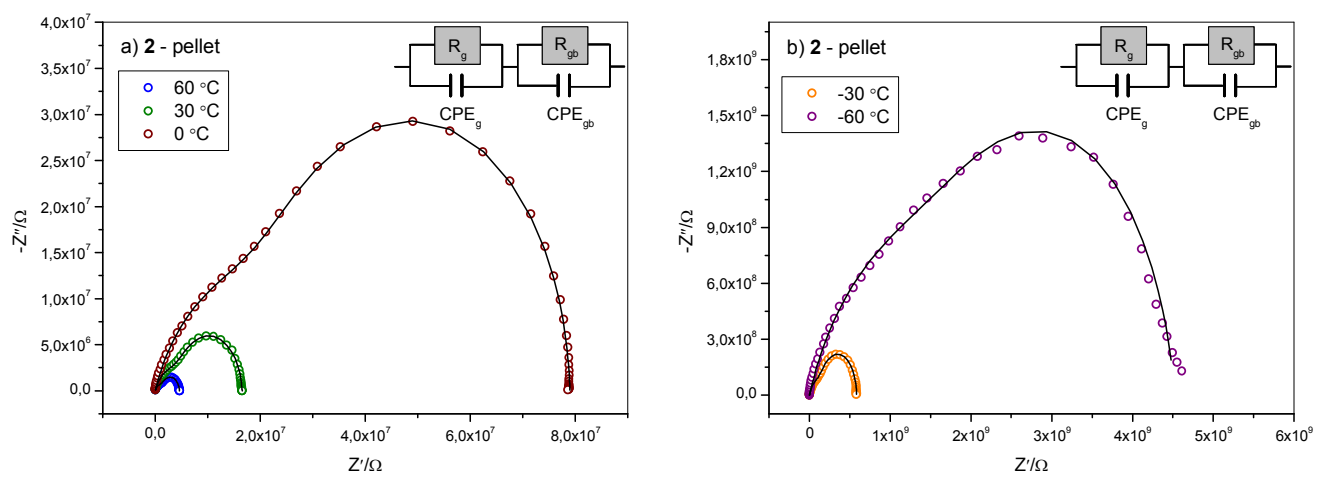

Figure S11 Impedance spectra at different temperatures and corresponding equivalent circuits for the pellet of compound 2 . The two impedance semicircles observed at all temperatures can be approximated by a series of two parallel R-CPE elements. The high frequency semicircle corresponds to the crystalline grains, while, low frequency one corresponds to the grain boundary. Circles denote experimental values; solid lines correspond to the best fit. The fitting parameters are given in Table S5 of the Supporting Information. 
Table S5 The fitting parameters of impedance spectra at different temperatures and calculated electrical conductivities for the pellet of compounds $\mathbf{1}$ and $\mathbf{2}$.

\begin{tabular}{|c|c|c|c|c|c|c|c|}
\hline \multirow[t]{2}{*}{ Sample } & \multirow[t]{2}{*}{$\mathrm{T}^{\circ}(\mathrm{C})$} & \multirow[t]{2}{*}{$R_{1} / \Omega$} & \multicolumn{2}{|c|}{$C P E_{I}$} & \multirow[t]{2}{*}{$R_{2} / \Omega$} & \multicolumn{2}{|c|}{$C P E_{2}$} \\
\hline & & & $A_{1} / \mathrm{s}^{\alpha} \Omega^{-1}$ & $\alpha_{1}$ & & $A_{2} / \mathrm{s}^{\alpha} \Omega^{-1}$ & $\alpha_{2}$ \\
\hline \multirow{5}{*}{ 1-pellet } & 60 & $1.93 \times 10^{5}$ & $9.16 \times 10^{-12}$ & 0.80 & $3.42 \times 10^{6}$ & $1.22 \times 10^{-8}$ & 0.78 \\
\hline & 30 & $2.41 \times 10^{6}$ & $5.57 \times 10^{-11}$ & 0.80 & $1.23 \times 10^{7}$ & $9.25 \times 10^{-10}$ & 0.66 \\
\hline & 0 & $2.73 \times 10^{7}$ & $8.14 \times 10^{-11}$ & 0.71 & $6.76 \times 10^{7}$ & $1.33 \times 10^{-10}$ & 0.88 \\
\hline & -30 & $2.24 \times 10^{8}$ & $4.63 \times 10^{-11}$ & 0.71 & $5.13 \times 10^{8}$ & $7.59 \times 10^{-11}$ & 0.91 \\
\hline & -60 & $1.39 \times 10^{9}$ & $2.38 \times 10^{-11}$ & 0.74 & $4.68 \times 10^{9}$ & $5.38 \times 10^{-11}$ & 0.83 \\
\hline \multirow{5}{*}{ 2-pellet } & 60 & $1.34 \times 10^{6}$ & $8.06 \times 10^{-11}$ & 0.76 & $3.29 \times 10^{6}$ & $1.25 \times 10^{-10}$ & 0.88 \\
\hline & 30 & $5.11 \times 10^{6}$ & $7.14 \times 10^{-11}$ & 0.75 & $1.14 \times 10^{7}$ & $4.79 \times 10^{-11}$ & 0.97 \\
\hline & 0 & $2.56 \times 10^{7}$ & $5.25 \times 10^{-11}$ & 0.74 & $5.34 \times 10^{7}$ & $3.80 \times 10^{-11}$ & 0.99 \\
\hline & -30 & $1.59 \times 10^{8}$ & $3.21 \times 10^{-11}$ & 0.75 & $4.26 \times 10^{8}$ & $3.63 \times 10^{-11}$ & 0.97 \\
\hline & -60 & $2.05 \times 10^{9}$ & $3.03 \times 10^{-11}$ & 0.68 & $2.48 \times 10^{9}$ & $7.93 \times 10^{-11}$ & 0.93 \\
\hline
\end{tabular}




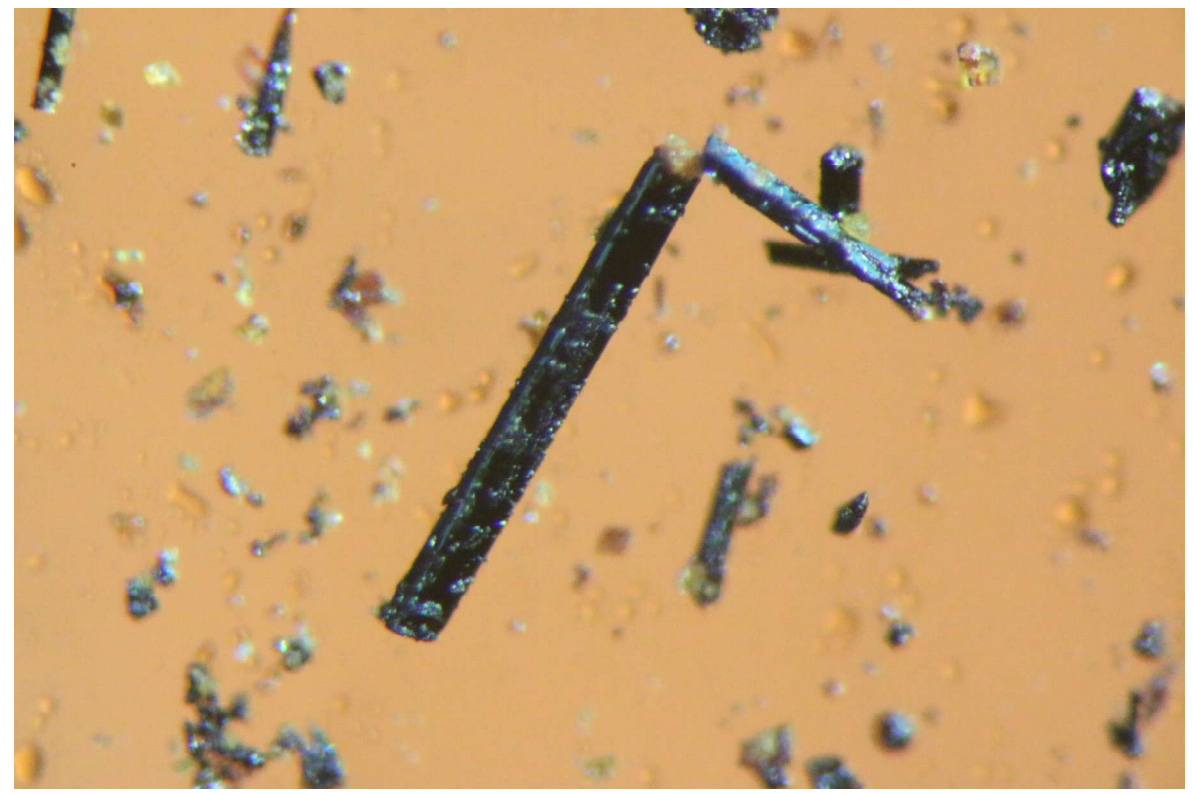

Figure S12 A Typical example of a needle-like orthorhombic single crystal of 2 (crystals of orthorhombic $\mathbf{1}$ are isomorphous) used for impedance spectroscopy measurement. The large crystal in the centre is $c a .1 .5 \mathrm{~mm}$ long.

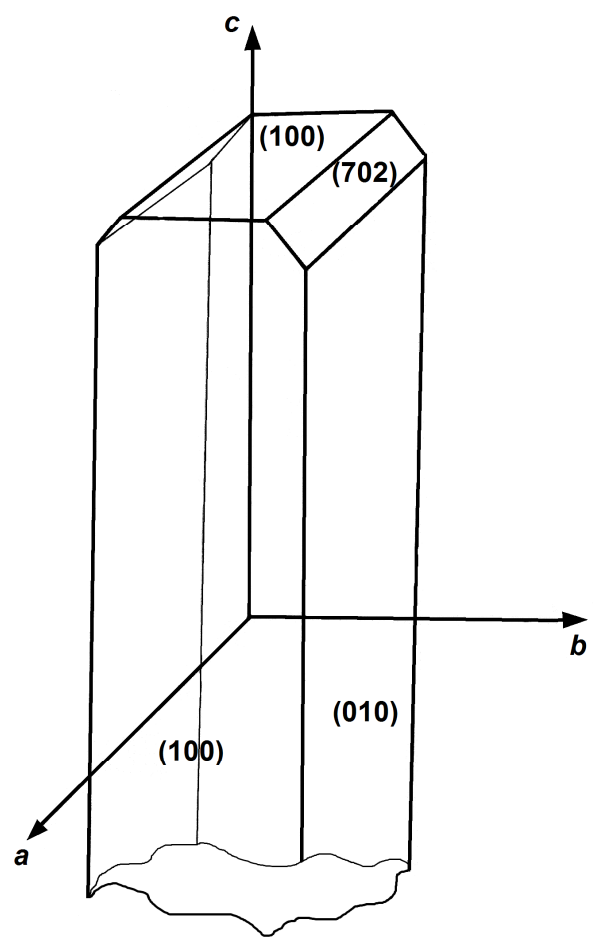

Figure S13 Schematic drawing of morphology of an idealized crystal of orthorhombic 1 and 2. Faces $\{702\}$ develop only exceptionally. 


\section{S6 Experimental details}

\section{S 6.1 Preparation}

All chemicals used in the syntheses were of p.a. grade, purchased from commercial sources (Merck, Sigma, Kemika) and used without purification. $N$ methylpyridinium iodide was prepared by slowly adding a solution of methyl iodide in acetone $(20 \mathrm{mmol}$ in $10 \mathrm{~mL})$ to an acetone solution of pyridine $(20 \mathrm{mmol}$ in $10 \mathrm{~mL})$ with stirring. Almost immediately colorless crystalline solid stared to appear. After mixing of the reagents, the solution was left to cool to $0{ }^{\circ} \mathrm{C}$, after which $\mathrm{N}$ methylpyridinium iodide was filtered and washed with cold acetone. Radical salts were prepared by a modification of the method first described by Torrey and Hunter $^{1,12}$ : excess of solid $N$-methylpyridinium iodide was added into a saturated solution of the quinone (in acetone or acetonitrile, $20 \mathrm{~mL}$ ). Diffraction-quality crystals were typically formed within $1-2$ hours, and the solution was then decanted. In the case of $\mathbf{1}$, kinetically favored triclinic polymorph crystallizes first (crystals typically form within 30 minutes), but later starts to decompose as termodinamically more stable orthorhombic polymorph begins to precipitate (upon standing in a solution for several hours, triclinic polymorph totally disappears).

Stability of the crystals was studied by TG/DTA (Shimadzu DTG-60H analyzer. Thermal analysis was carried out on a Mettler Toledo DSC823 module in sealed aluminum pans $(40 \mu \mathrm{L})$, heated in flowing nitrogen $\left(150 \mathrm{~mL} \mathrm{~min}^{-1}\right)$ at heating rate of $7{ }^{\circ} \mathrm{C} \mathrm{min}^{-1}$. The mass of the sample was $9.592 \mathrm{mg}$. Data collection and analysis were performed using the program package $\mathrm{STAR}^{\mathrm{e}}$ Software $9.01^{13}$. IR spectra were measured by $\mathrm{KBr}$ pellet technique using a Bruker Alpha-T spectrometer. 
S 6.2 Magnetic studies (EPR spectroscopy and SQUID)

Magnetization $M$ was measured using MPMS-5 commercial SQUID magnetometer. Temperature dependence of magnetization of compounds $\mathbf{1}$ and $\mathbf{2}$ was measured in different magnetic fields, in temperature range $2-300 \mathrm{~K}$, using two modes: after cooling in zero-field (ZFC), and after cooling in magnetic field (FC) in which measurement is performed during heating. Also, high temperature inset was used to measure magnetization above $400 \mathrm{~K}$. Field dependences of magnetization, $M(H)$, i.e. magnetic hysteresis loops, were measured at several stable temperatures in fields up to $50 \mathrm{kOe}$. Measured magnetic moments of the samples were corrected against the recorded sample holder contribution.

The EPR spectra were acquired using a Bruker ELEXYS E580 X band spectrometer, equipped with an Oxford Instruments model DTC2 temperature controller, operating in the range $4-300 \mathrm{~K}$. EPR spectra in the range $293-473 \mathrm{~K}$ were recorded on a Varian E-109 X-band spectrometer using a Bruker ER 4111 VT variable-temperature unit with a flow of $\mathrm{N}_{2}$ gas. Precautions to avoid undesirable spectral distortions and line broadenings, such as those arising from microwave power saturation and magnetic field over modulation, were also taken into account. A Varian strong pitch standard ( $\mathrm{g}=2.0028)$ sample was used to calibrate the absolute values of the integrated intensity and to obtain accurate g-values of the samples. The number of spins (spin/g) in samples was calculated from the EPR signal areas determined by double integration of the spectrum. 


\section{S6.3 Impedance spectroscopy}

Electrical conductivity measurements using impedance spectroscopy (Novocontrol Alpha-N dielectric analyzer) were performed on single crystals of orthorhombic 1 and $\mathbf{2}$ along their crystallographic $c$ axis in the frequency range from $0.01 \mathrm{~Hz}$ to $1 \mathrm{MHz}$ and temperature range from $-90{ }^{\circ} \mathrm{C}$ to $90{ }^{\circ} \mathrm{C}$. For electrical contact, silver paint electrodes were deposited on the opposite surfaces $\{001\}$ of the crystals. Impedance measurements were also performed on these compounds in their polycrystalline phases by pressing powders of the samples between brass electrodes ( 4 $\mathrm{mm}$ in diameter) into approximately $1 \mathrm{~mm}$-thick pellets.

The impedance spectra were analyzed by equivalent-circuit modelling with a complex nonlinear least-squares fitting procedure (ZView software package). Ideally, the impedance semicircle passes through the origin of a complex plot and gives a lowfrequency intercept on the real axis corresponding to the resistance $\mathrm{R}$ of the sample. The equivalent circuit that represents such an ideal semicircle is a parallel combination of resistor $(\mathrm{R})$ and capacitor $(\mathrm{C})$. Because our experimental data showed depressed semicircle(s) with the center below the real axis, we used a constant-phase element (CPE) instead of ordinary capacitor. The CPE is an empirical impedance function of the type: $\mathrm{Z}_{\mathrm{CPE}}=1 /\left[\mathrm{A}(\mathrm{i} \omega)^{\alpha}\right]$, where $\omega=2 \pi \mathrm{f}$, $\mathrm{f}$ is the measuring frequency, $\mathrm{I}$ $=(-1)^{1 / 2}$ the imaginary unit, A a constant, and $\alpha$ a power-law exponent with value in the range $0<\alpha<1$. 


\section{S6.4 Crystallography}

Single crystal measurements were performed on an Oxford Diffraction Xcalibur Nova R (microfocus $\mathrm{Cu}$ tube) equipped with an Oxford Instruments CryoJet liquid-nitrogen cooling device. Program package CrysAlis PRO ${ }^{14}$ was used for data reduction and multi-scan absorption correction. The structures were solved using SHELXS97 ${ }^{15}$ and refined with SHELXL97 ${ }^{15}$. The models were refined using the full-matrix least squares refinement; all non-hydrogen atoms were refined anisotropically. Hydrogen atoms were modelled as riding entities for triclinic $\mathbf{1}$ (due to inferior quality of the crystals) and for $\mathbf{2}$; for orthorhombic $\mathbf{1}$ they were located from electron density and refined as free, isotropic, entities. Structures of triclinic 1 were of inferior quality due to the presence of charge density wave (CDW). It is a common phenomenon in Peierls-distorted stacks of diamagnetic radicals, ${ }^{16,17}$ and is usually more pronounced at low temperatures. During refinement it has been detected as high, but meaningless, residual density (Table S6); also satellite peaks were present close to main Bragg peaks in the raw diffraction data. These satellite peaks can be approximately designated by a modulation vector of $(0,0.13,0.17)$. However, due to a small number and intensity of the satellite peaks, refinement of the modulated structure using JANA2006 software ${ }^{18}$ did not produce any improvement.

Molecular geometry calculations were performed by PLATON ${ }^{19}$, and molecular graphics were prepared using ORTEP-3 ${ }^{5}$, and CCDC-Mercury ${ }^{20}$. Crystallographic and refinement data for the structures reported in this paper are shown in Table S6.

Supplementary crystallographic data for this paper can be obtained free of charge via www.ccdc.cam.ac.uk/conts/retrieving.html (or from the Cambridge Crystallographic Data Centre, 12, Union Road, Cambridge CB2 1EZ, UK; fax: +44 1223 336033; or deposit@ccdc.cam.ac.uk). CCDC 1468772-1468777 contain the supplementary crystallographic data for this paper. 
Table S6 Crystallographic, data collection and structure refinement details.

\begin{tabular}{|c|c|c|c|}
\hline Compound & $\begin{array}{l}\text { 1, } \\
\text { triclinic, } 100 \mathrm{~K}\end{array}$ & $\begin{array}{l}\text { 1, } \\
\text { triclinic, RT }\end{array}$ & $\begin{array}{l}\text { 1, } \\
\text { orthorhombic, } 100 \mathrm{~K}\end{array}$ \\
\hline Empirical formula & $\mathrm{C}_{12} \mathrm{H}_{8} \mathrm{Cl}_{4} \mathrm{NO}_{2}$ & $\mathrm{C}_{12} \mathrm{H}_{8} \mathrm{Cl}_{4} \mathrm{NO}_{2}$ & $\mathrm{C}_{12} \mathrm{H}_{8} \mathrm{Cl}_{4} \mathrm{NO}_{2}$ \\
\hline Formula wt. $/ \mathrm{g} \mathrm{mol}^{-1}$ & 339.99 & 339.99 & 339.99 \\
\hline Crystal dimensions / $\mathrm{mm}$ & $0.15 \times 0.04 \times 0.03$ & $0.30 \times 0.05 \times 0.04$ & $0.20 \times 0.05 \times 0.04$ \\
\hline Space group & $P \overline{1}$ & $P \overline{1}$ & P nma \\
\hline$a / \AA$ & $7.2882(6)$ & $7.3502(3)$ & $18.0641(8)$ \\
\hline$b / \AA$ & $9.2250(6)$ & $9.2643(6)$ & $18.5943(11)$ \\
\hline$c / \AA$ & $10.3823(7)$ & $10.5199(6)$ & $3.77579(19)$ \\
\hline$\alpha /{ }^{\circ}$ & $73.456(6)$ & $73.287(5)$ & 90 \\
\hline$\beta /{ }^{\circ}$ & $72.914(7)$ & $73.041(5)$ & 90 \\
\hline$\gamma / \circ$ & $75.675(6)$ & $76.484(5)$ & 90 \\
\hline $\mathrm{Z}$ & 2 & 2 & 4 \\
\hline$V / \AA^{3}$ & $629.31(8)$ & $647.41(6)$ & $1268.24(11)$ \\
\hline$D_{\text {calc }} / \mathrm{g} \mathrm{cm}^{-3}$ & 1.794 & 1.744 & 1.781 \\
\hline$\mu / \mathrm{mm}^{-1}$ & 8.525 & 8.287 & 8.461 \\
\hline$\Theta$ range $/{ }^{\circ}$ & $4.58-75.30$ & $4.52-75.86$ & $4.76-75.90$ \\
\hline$T / \mathrm{K}$ & $100(2)$ & 293(2) & $100(2)$ \\
\hline Radiation vawelength & $1.54179(\mathrm{CuK \alpha})$ & $1.54179(\mathrm{CuK \alpha})$ & $1.54179(\mathrm{CuK \alpha})$ \\
\hline Diffractometer type & Xcalibur Nova & Xcalibur Nova & Xcalibur Nova \\
\hline Range of $h, k, l$ & $\begin{array}{l}-8<h<9 \\
-10<k<11 \\
-11<l<12\end{array}$ & $\begin{array}{l}-9<h<5 \\
-11<k<11 \\
-13<l<11\end{array}$ & $\begin{array}{l}-22<h<19 \\
-20<k<23 \\
-3<l<4\end{array}$ \\
\hline Reflections collected & 5093 & 5653 & 3255 \\
\hline Independent reflections & 2563 & 2660 & 1351 \\
\hline $\begin{array}{l}\text { Observed reflections } \\
(I \geq 2 \sigma)\end{array}$ & 2170 & 2273 & 1158 \\
\hline Absorption correction & Multi-scan & Multi-scan & Multi-scan \\
\hline$R_{\text {int }}$ & 0.0705 & 0.0399 & 0.0582 \\
\hline$R(F)$ & 0.0844 & 0.0523 & 0.0462 \\
\hline$R_{w}\left(F^{2}\right)$ & 0.2275 & 0.1507 & 0.1221 \\
\hline Goodness of fit & 1.043 & 1.016 & 1.050 \\
\hline $\mathrm{H}$ atom treatment & Riding & Riding & Free \\
\hline No. of parameters & 173 & 173 & 109 \\
\hline No. of restraints & 0 & 0 & 0 \\
\hline$\Delta \rho_{\max }, \Delta \rho_{\min }\left(\mathrm{e} \AA^{-3}\right)$ & $1.608 ;-1.147$ & $0.617:-0.487$ & $0.500 ;-0.626$ \\
\hline
\end{tabular}


Table S6 Cont'd.

\begin{tabular}{|c|c|c|c|}
\hline Compound & $\begin{array}{l}\text { 1, } \\
\text { orthorhombic, RT }\end{array}$ & $\begin{array}{l}2, \\
\text { orthorhombic } 100 \mathrm{~K}\end{array}$ & $\begin{array}{l}\text { 2, orthorhombic, } \\
\text { RT }\end{array}$ \\
\hline Empirical formula & $\mathrm{C}_{12} \mathrm{H}_{8} \mathrm{Cl}_{4} \mathrm{NO}_{2}$ & $\mathrm{C}_{12} \mathrm{H}_{8} \mathrm{Br}_{4} \mathrm{NO}_{2}$ & $\mathrm{C}_{12} \mathrm{H}_{8} \mathrm{Br}_{4} \mathrm{NO}_{2}$ \\
\hline Formula wt. / $\mathrm{g} \mathrm{mol}^{-1}$ & 339.99 & 517.83 & 517.83 \\
\hline Crystal dimensions / mm & $0.25 \times 0.10 \times 0.08$ & $0.20 \times 0.10 \times 0.07$ & $0.35 \times 0.10 \times 0.09$ \\
\hline Space group & P nma & P nma & P nma \\
\hline$a / \AA$ & $18.1880(4)$ & $18.639(5)$ & $18.7998(4)$ \\
\hline$b / \AA$ & $18.7424(4)$ & $18.680(5)$ & $18.8174(5)$ \\
\hline$c / \AA$ & $3.84110(10)$ & $3.895(5)$ & $3.95910(10)$ \\
\hline$\alpha /{ }^{\circ}$ & 90 & 90 & 90 \\
\hline$\beta /{ }^{\circ}$ & 90 & 90 & 90 \\
\hline$\gamma / \circ$ & 90 & 90 & 90 \\
\hline Z & 4 & 4 & 4 \\
\hline$V / \AA^{3}$ & $1309.38(5)$ & $1356.1(18)$ & $1400.58(6)$ \\
\hline$D_{\text {calc }} / \mathrm{g} \mathrm{cm}^{-3}$ & 1.725 & 2.536 & 2.456 \\
\hline$\mu / \mathrm{mm}^{-1}$ & 8.195 & 14.472 & 14.013 \\
\hline$\Theta$ range $/{ }^{\circ}$ & $4.72-75.96$ & $3.35-75.86$ & $3.32-75.58$ \\
\hline$T / \mathrm{K}$ & $293(2)$ & $100(2)$ & $293(2)$ \\
\hline Radiation vawelength & $1.54179(\mathrm{CuK \alpha})$ & $1.54179(\mathrm{CuK \alpha})$ & $1.54179(\mathrm{CuK \alpha})$ \\
\hline Diffractometer type & Xcalibur Nova & Xcalibur Nova & Xcalibur Nova \\
\hline Range of $h, k, l$ & $\begin{array}{l}-21<h<21 ; \\
-23<k<23 ; \\
-4<l<4\end{array}$ & $\begin{array}{l}-22<h<23 ; \\
-20<k<23 ; \\
-4<l<4\end{array}$ & $\begin{array}{l}-20<h<23 ; \\
-18<k<23 ; \\
-2<l<4\end{array}$ \\
\hline Reflections collected & 9298 & 4582 & 3941 \\
\hline Independent reflections & 1398 & 1436 & 1463 \\
\hline $\begin{array}{l}\text { Observed reflections } \\
(I \geq 2 \sigma)\end{array}$ & 1313 & 1328 & 1339 \\
\hline Absorption correction & Multi-scan & Multi-scan & Multi-scan \\
\hline$R_{\text {int }}$ & 0.0292 & 0.0357 & 0.0232 \\
\hline$R(F)$ & 0.0275 & 0.0368 & 0.0289 \\
\hline$R_{w}\left(F^{2}\right)$ & 0.0741 & 0.098 & 0.0768 \\
\hline Goodness of fit & 1.051 & 1.083 & 1.051 \\
\hline $\mathrm{H}$ atom treatment & Free & Riding & Riding \\
\hline No. of parameters & 109 & 91 & 92 \\
\hline No. of restraints & 0 & 0 & 0 \\
\hline$\Delta \rho_{\max }, \Delta \rho_{\min }\left(\mathrm{e} \AA^{-3}\right)$ & $0.241 ;-0.255$ & $0.553 ;-0.423$ & $1.669 ;-0.836$ \\
\hline
\end{tabular}




\section{S7 References}

(1) Molčanov, K.; Kojić-Prodić, B.; Babić, D.; Žilić, D.; Rakvin, B. CrystEngComm $2011,13,5170-5178$.

(2) Molčanov, K.; Kojić-Prodić, B.; Babić, D.; Pajić, D.; Novosel, N.; Zadro, K. CrystEngComm 2012, 14, 7958-7964.

(3) Molčanov, K.; Babić, D.; Kojić-Prodić, D.; Stare, J.; Maltar-Strmečki, N.; Androš, L. Acta Crystallogr. B, 2014, B70, 181-190.

(4) Cremer D.; Pople, J. A. J. Am. Chem. Soc., 1975, 97, 1354-1358.

(5) Farrugia, L. J. J. Appl. Cryst., 1997, 30, 565.

(6) Puranik, M.; Chandrasekhar, J.; Snijders, J. G.; Umapathy, s. J. Phys. Chem. A, 2001, 105, 10562-10569.

(7) Miller, J. S.; Dixon, D. A. Science, 1987, 235, 871-873.

(8) Boesch, S. E.; Wheeler, R. A. J. Phys. Chem. A, 1997, 101, 8351-8359.

(9) Boesch, S. E.; Wheeler, R. A. J. Phys. Chem., 1995, 99, 8125-8134.

(10) Zhang, Y.; Zhang, F.; Ma, K.; Tang, G. Spectrochim. Acta A, 2013, 105, 352358.

(11) Arenas, J. F.; López Tocón, I.; Otero, J. C.; Marcos, J. I. J. Mol. Struct., 1996, 410-411, 443-446.

(12) Torrey, H. A.; Hunter, W. H. J. Am. Chem. Soc., 1912, 34, 702-716.

(13) STAR ${ }^{e}$ Software V.9.01., Mettler-Toledo GmbH, 2006.

(14) CrysAlis PRO, Oxford Diffraction Ltd., U.K., 2007.

(15) Sheldrick, G. M. Acta Crystallogr. 2008, A64, 112-122.

(16) Monceau, P. Adv. Phys., 2012, 61, 625-581.

(17) Zhu, X.; Cao, Y.; Zhang, J.; Plummer, E. W.; Guo, J. Proc. Natl. Acad. Sci. USA, 2015, 112, 2367-2371.

(18) Petřiček, V., Dušek, M. \& Palatinus, L. Z. Kristallogr., 2014, 229, 345-352.

(19) Spek, A. L. J. Appl. Cryst. 2003, 36, 7-13.

(20) Macrae, C. F.; Edgington, P. R.; McCabe, P.; Pidcock, E.; Shields, G. P.; Taylor, R.; Towler, M.;. van de Streek, J. J. Appl. Cryst., 2006, 39, 453-457. 